\title{
Neuroendocrine Tumor Grade 2 of the Nasal Cavity: Case Report and Review of Literature
}

\author{
Min Jun Shin, MD, Seung Jin Park, MD and Nam Kyung Yeo, MD, PhD \\ Department of Otorhinolaryngology, Gangneung Asan Hospital, University of Ulsan College of Medicine, \\ Gangneung, Korea
}

\begin{abstract}
- ABSTRACT -
Neuroendocrine tumors (NETs) of the sinonasal tract are rare in occurrence. According to the 2017 World Health Organization classification of the primary head and neck neuroendocrine carcinomas, they can be classified as follows: well-differentiated, moderately differentiated, and poorly differentiated types. Among these, welldifferentiated and moderately differentiated neuroendocrine carcinomas of the sinonasal tract are extremely rare. Based on a recent proposal, well-differentiated and moderately differentiated neuroendocrine carcinomas are also called neuroendocrine tumor grade 1 and 2, respectively. Because of its rarity and the lack of studies, treatment guidelines for NETs of the sinonasal tract have not been established yet. We report a case of NET grade 2 of the nasal cavity in a 46-year-old man treated by endoscopic sinus surgery. To the best of our knowledge, this is the first case report on an NET grade 2 of the nasal cavity in South Korea. (J Clinical Otolaryngol 2020;31:228-233)
\end{abstract}

KEY WORDS: Neuroendocrine tumor $\cdot$ Nasal cavity $\cdot$ Carcinoid tumor.

\section{Introduction}

Neuroendocrine tumors (NETs) of the sinonasal tract are rare. They have been reported under various names. According to the 2017 World Health Organization (WHO 2017) classification of the primary head and neck neuroendocrine carcinomas (NECs), they can be classified as follows: i) well-differentiated (typical carcinoid), ii) moderately differentiated (atypical carcinoid), and iii) poorly differentiated with small cell and large cell types. ${ }^{1)}$ Among these, well-differentiated and moderately differentiated NECs of the nasal cavity and paranasal sinuses are extremely rare. ${ }^{2)}$ Based on a recent proposal, well-differentiated and moderately differentiated NECs are also called NET grade 1 (NET-G1) and 2 (NET-G2), respectively. ${ }^{3)}$ Due to their scarcity and the lack of studies, treatment guidelines for
NETs of the sinonasal tract have not been established yet. However, many studies have shown that the tumor histology correlates closely with the patient prognosis. We report a case of NET grade 2 of the nasal cavity in a 46-year-old man who was treated by surgery using sinus endoscopy with pathological findings. Considering the WHO 2017 classification, which has de-emphasized the terms "typical carcinoid" and "atypical carcinoid", we mainly used the term "NET-G1 or NET-G2" instead of "typical carcinoid" or "atypical carcinoid". 1) To the best of our knowledge, this is the first report on an NET grade 2 of the nasal cavity and paranasal sinuses in South Korea. We present this case with a review of the literature to provide a basic understanding of sinonasal NETs and general assistance in deciding the treatment strategy.

논문접수일: 2020년 6월 30일 / 논문수정일: 2020년 8월 20일 / 심사완료일: 2020년 8월 25일

교신저자: 여남경, 25440 강원도 강릉시 사천면 방동길 38 , 울산대학교 의과대학 강릉아산병원 이비인후과학교실

전화: (033) 610-3309 ·전송: (033) 642-3189·E-mail: newnew1@ hanmail.net 


\section{Case Report}

A 46-year-old man presented with frequent left-sided epistaxis and watery rhinorrhea of over 3 months' duration. He also developed nasal obstruction of the same side. There were no associated comorbidities. The nasal endoscopy showed a well-outlined reddish mass in the left sphenoethmoidal recess (Fig. 1A). Computed tomography (CT) scan revealed a mild enhancing mass, which had a stalk from the nasal septum with mild sinusitis of both the maxillary and ethmoid sinuses. Moreover, there was no bony destruction (Fig. 2). We performed biopsy of the mass by endoscopic endonasal resection with middle meatal antrostomy and anterior ethmoidectomy on both the sides under general anesthesia. We achieved complete removal of the mass using nasal endoscopy. Microscopic evaluation of the tumor cells revealed neuroendocrine-like features (Fig. 3 ). They were composed of round or ovoid cells with trabecular pattern. Mitotic count was eight per 10 high power fields. The tumor cells expressed immunoreactivity to synaptophysin; the Ki-67 staining showed 3 to $4 \%$
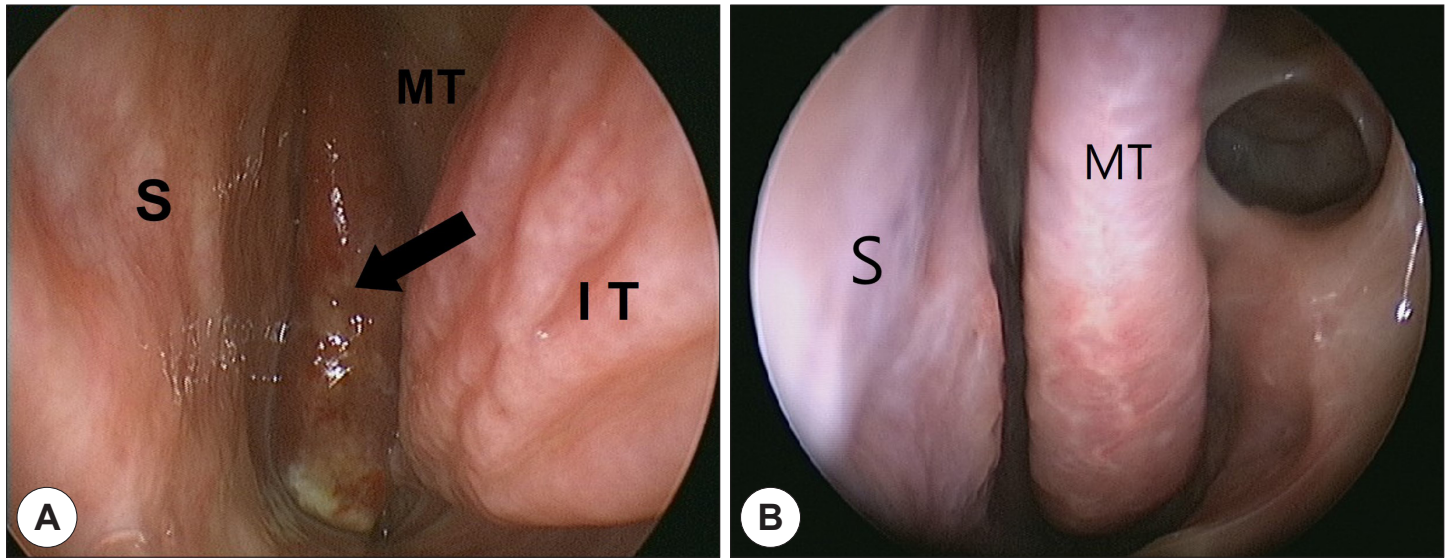

Fig. 1. Endoscopic findings. (A) Preoperative nasal endoscopy reveals a reddish mass extending from the left sphenoethmoidal recess to the left nasal floor. (B) After 3-year follow-up, postoperative endoscopy shows no recurrence. (MT: middle turbinate, $\mathrm{S}$ : nasal septum, IT : inferior turbinate, and arrow: mass).
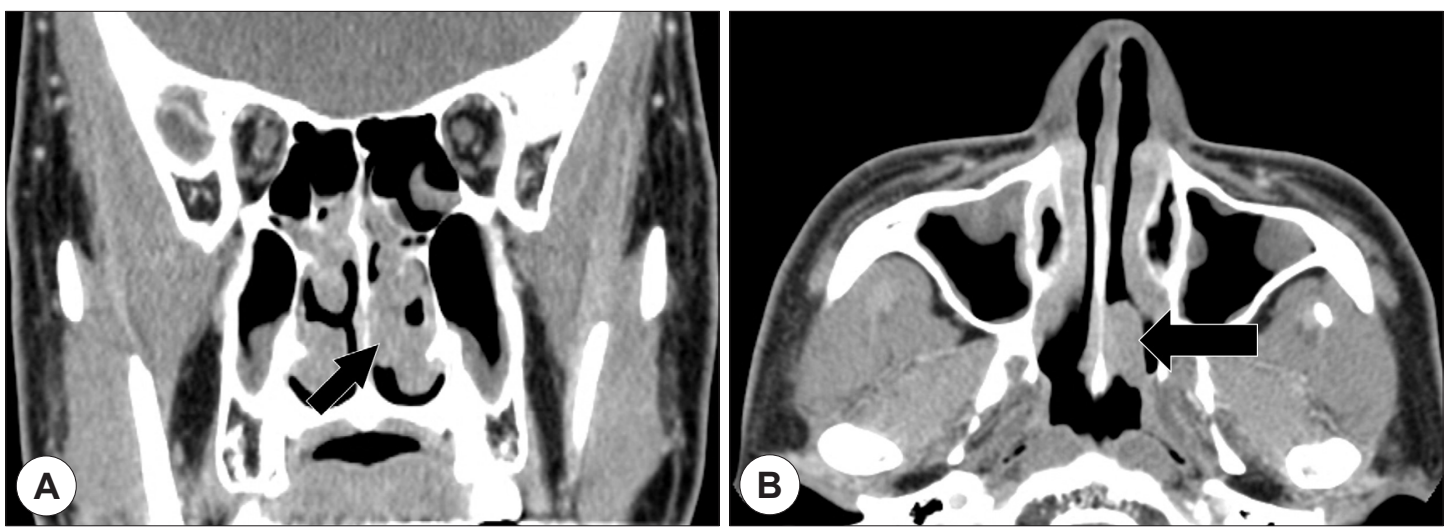

Fig. 2. Preoperative computed tomography (CT) scans of neuroendocrine tumor grade 2 of the nasal cavity. A soft tissue mass with mild enhancement (black arrow) is noted in coronal (A) and axial (B) view. 

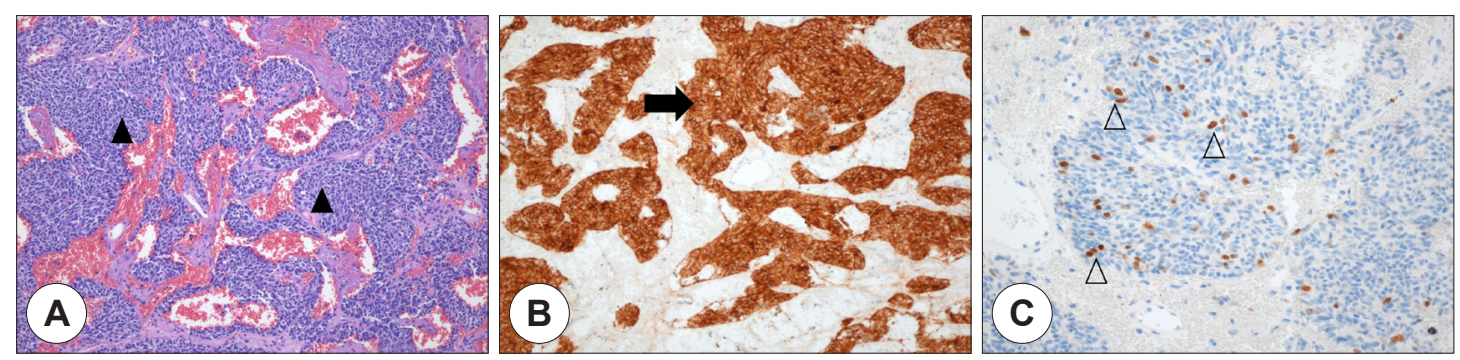

Fig. 3. Histopathology and immunohistochemistry. (A) Microscopic findings shows irregular trabecular pattern separated by fibroconnective stroma (black arrow heads, hematoxylin and eosin, 100×). (B) Cytoplasm of tumor cells is positive with synaptophysin (black arrow, 100×). (C) Immunohistochemical analysis shows the proliferation Ki-67 index of 3 to $4 \%$ (white arrow heads, $200 \times$ ).

proliferation rate in the immunohistochemical stains. Pathological findings were conclusive for atypical carcinoid at the time of diagnosis. There were no subsequent adjuvant treatments. After 3 years follow-up, there are no signs of recurrence or metastasis (Fig. 1B).

\section{Discussion}

Squamous cell carcinoma is the most common malignant tumor in the nasal cavity and paranasal sinuses, followed by adenocarcinoma, malignant lymphoma, sinonasal undifferentiated carcinoma, malignant melanoma, and olfactory neuroblastoma. ${ }^{4}$ NECs of the head and neck are extremely rare disease regardless of differentiation or subtype. They comprise $5 \%$ of the sinonasal malignancies. ${ }^{5}$ Limited cases have reported small cell NEC, the most common type of NEC. NET-G1 and NET-G2 in the nasal cavity and paranasal sinuses are exceedingly rare, only sporadic cases have been reported in the literature till date. ${ }^{6}$

Currently, WHO definitions categorize NECs according to their anatomic site because it is widely recognized that every anatomical location has its own individuality. However, Rindi et al. have proposed the following three grading parameters of prognostic relevance regardless of the anatomic sites:

i. The mitotic count should usually be expressed as mitoses per $\mathrm{mm}^{2}$ area. ii. The Ki-67 cell-labeling index.

iii. The presence or absence of necrosis. ${ }^{3)}$

Given that histologic grading closely correlates with the patient prognosis, otolaryngologists should request these three parameters to the pathologists while diagnosing NETs of the head and neck. Shah et al. proposed that NECs of the sinonasal tract are graded using the criteria set forth by the WHO for pulmonary NET. NET-G1 has uniform nuclei with stripped chromatin, clear or eosinophilic cytoplasm, and absence of necrosis. NET-G1 has $<2$ mitoses per 10 high power fields and the Ki-67 index is $\leq 2 \%$. NET-G2 can have mild cytologic atypia, patch necrosis, and has between 2 and 10 mitoses per 10 high power fields; the Ki-67 index is between 3 and 20\%. ${ }^{7)}$ However, the Ki-67 index is not currently required for classification or predicting prognosis.

Primary NECs of the head and neck including larynx are categorized by the WHO 2017 classification of the head and neck tumors as follows: well-differentiated, moderately differentiated, and poorly differentiated with small cell and large cell types. This classification was established based on the 5-year survival rate of $100,52.8,19.3$ and $15.3 \%$ for each diagnostic category. ${ }^{1)}$ In a recent study, Klöppel et al. defined NETs with well-differentiated and moderately differentiated carcinomas as neuroendocrine tumors, grade 1 (NET-G1) and 2 (NET-G2), respectively. In addition, the poorly 
differentiated carcinomas are defined as NEC. ${ }^{8)}$ Based on a recent proposal, we also defined "well-differentiated" and "moderately differentiated" as "NET-G1" and "NET-G2," respectively. This nomenclature is also in accordance with recent classification of pulmonary NETs. ${ }^{3)}$ However in this case report, we tried to use the original terms as far as possible when citing previous literature to prevent ambiguity.

We have reviewed 23 cases of NET-G1 and NET-G2, which are available in full-text in English, including our case (Table 1). Nineteen of 23 patients chose surgery as treatment; seven patients added radiotherapy or chemotherapy. Only three patients chose concurrent chemoradiation therapy alone. Among them, one case could not undergo surgery due to the skull base involvement. Ten patients reported the mitotic index and only eight patients reported both the mitotic index and Ki-67 index. No agreement for adequate treatment has been established yet. However, we could confirm majority of patients of NET-G1 and G2 underwent surgery as the principal treatment. Two of 19 low-grade NET patients who underwent surgery died due to the disease. One of 19 patients showed local recurrence.

According to Van der Laan et al., treatment options for patients with well-differentiated and moderately differentiated NECs often include surgery. Surgery is advocated as the mainstay of all treatment options for curative purpose of sinonasal NECs. These authors proposed that well-differentiated NECs could be treated by surgery and monotherapy. The patients with moderately differentiated NECs could require an aggressive approach including postoperative radiotherapy. The patients with poorly differentiated type should be added radiotherapy. The authors reported that the application of chemotherapy did not show any benefit regarding survival rate. Contrary to the other head and neck cancers, tumor staging does not predict survival and has limited value in deciding the treatment strategy. ${ }^{9)}$ Combined treatment based on surgery is associated with significantly better disease-free survival and overall survival as compared to the treatment without surgery regardless of histologic differentiation. ${ }^{10)}$

Kao et al. concluded that, generally, well-differentiated and moderately differentiated NECs are resistant to chemotherapy. However, these histological types of sinonasal NETs usually show better 5-year survival rate; whereas, large cell and small cell NECs may respond to chemotherapy with worse 5 -year survival rate. ${ }^{11)}$ Maharaj et al. reported increased biologic aggression with increasing tumor grades in the non-small cell neuroendocrine carcinoma. ${ }^{12)}$ Studies about sinonasal NECs have shown that the tumor stage does not significantly affect the survival rate. The treatment response and prognosis of sinonasal NECs are closely related to differentiation grade. ${ }^{2,9,11)}$

Fitzek et al. proposed that neoadjuvant treatment in the form of chemotherapy followed by radiotherapy showed promising results for the treatment of NECs. ${ }^{13)}$ Bhattacharyya et al. and Babin et al. have also proposed chemotherapy followed by radiation as initial treatment for sinonasal NECs. ${ }^{14,15)} \mathrm{SU}$ et al. proposed that neoadjuvant chemotherapy followed by either chemoradiation or surgery and postoperative radiation is a promising strategy for treatment of sinonasal NECs. Neoadjuvant chemotherapy could be helpful for patients with NECs of the sinonasal tract. ${ }^{2)}$ These authors also proposed that the patients with the foveal or orbital infiltration and tumor originating outside of the nasal cavity could be predictors of poor outcome. Many authors have a consensus about multimodality treatment approach for sinonasal NETs. ${ }^{16}$

Only a single case of NET-G1 was reported in South Korea. ${ }^{17)}$ To the best of our knowledge, this is the first case report of NET grade 2 in South Korea. Overall, there are no treatment guidelines available regarding sinonasal NETs. Although many reports advocate surgery as principal treatment, various treatment approaches have been performed with no definite guidelines and 


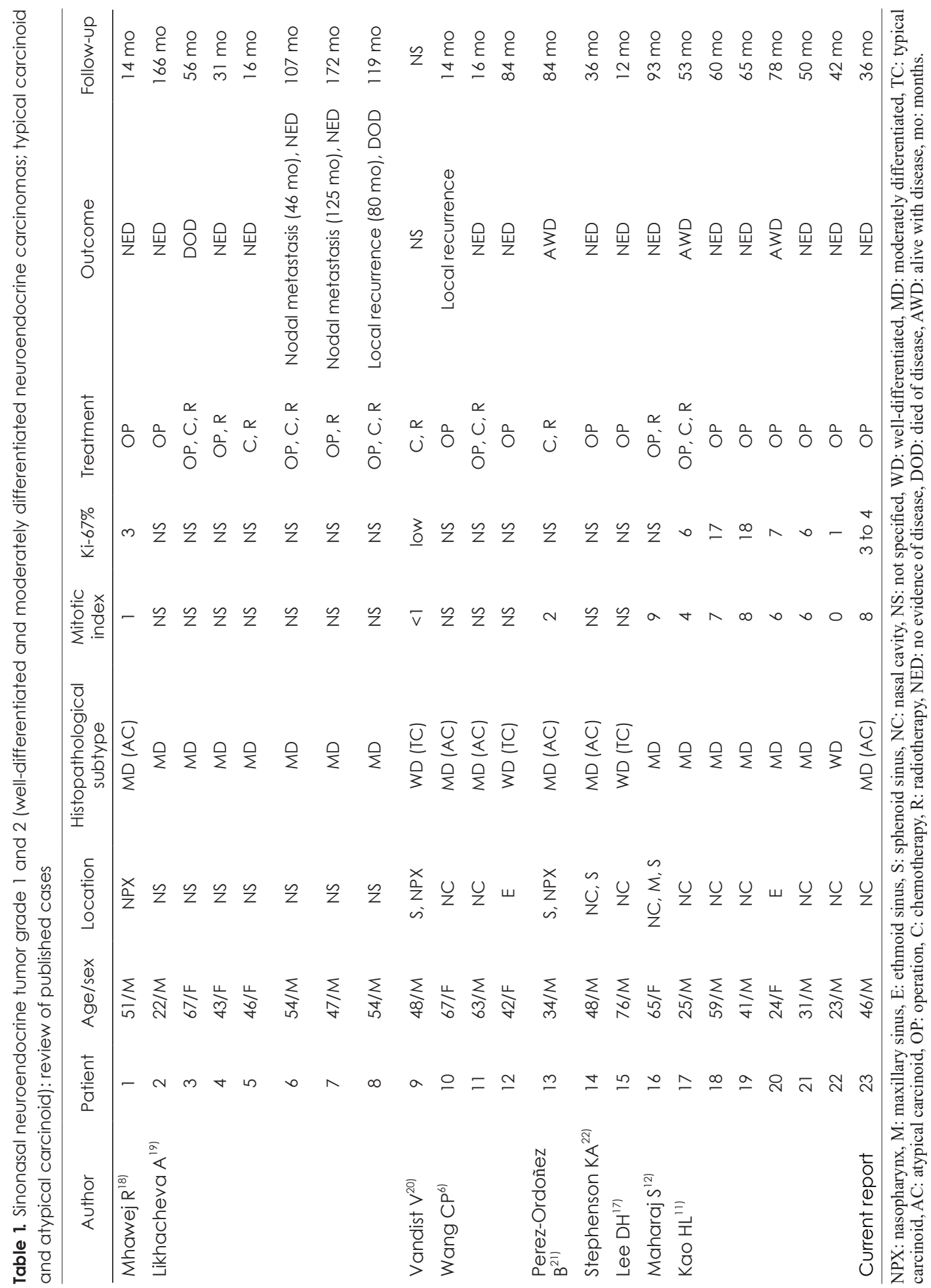


different outcomes and prognoses have been reported. Because of confusing terminology between reported cases and lack of cases, it is difficult to draw strong recommendations. Therefore, application of uniform nomenclatures for the head and neck NET is needed. Moreover, we advocate that histologic grading including presence of necrosis, the mitotic index, and the Ki67 index have been reported to compare tumor identity. We also advocate that surgery has to be the main treatment strategy, as performed in this reported case of sinonasal NET. Large scale and high quality studies are required in the future for clinical relevance about sinonasal NETs that can allow definite treatment guidelines based on histological grading. Further studies about parameters, such as the Ki-67 index, are also required to predict the prognosis.

\section{REFERENCES}

1) Perez-Ordoñez B. Neuroendocrine carcinomas of the larynx and head and neck: challenges in classification and grading. Head Neck Pathol 2018;12(1):1-8.

2) Su SY, Bell D, Hanna EY. Esthesioneuroblastoma, neuroendocrine carcinoma, and sinonasal undifferentiated carcinoma: differentiation in diagnosis and treatment. Int Arch Otorhinolaryngol 2014;18(2):149-56.

3) Rindi G, Klimstra DS, Abedi-Ardekani B, Asa SL, Bosman FT, Brambilla E, et al. A common classification framework for neuroendocrine neoplasms: an International Agency for Research on Cancer (IARC) and World Health Organization (WHO) expert consensus proposal. Mod Pathol 2018;31(12):1770-86.

4) Wani SQ, Dar IA, Khan T, Lone MM. Primary sino-nasal neuroendocrine carcinoma: a rare tumor. Cureus 2019; 11(2):e4144.

5) Lahma J, Hejjouji R, Gicquel P, Essakalli L. Large cell neuroendocrine carcinoma of the nasal cavity: an extremely rare and new distinct entity. Pan Afr Med J 2018;30:188.

6) Wang CP, Hsieh CY, Chang YL, Lou PJ, Yang TL, Ting LL, et al. Postirradiated neuroendocrine carcinoma of the sinonasal tract. Laryngoscope 2008;118(5):804-9.

7) Shah K, Perez-Ordóñez B. Neuroendocrine neoplasms of the sinonasal tract: neuroendocrine carcinomas and olfactory neuroblastoma. Head Neck Pathol 2016;10(1):85-94.

8) Klöppel G, Franchi A, Matias-Guiu X. Neuroendocrine neoplasms, olfactory neuroblastomas and paragangliomas of the head and neck. In: Cardesa A, Slootweg P, Gale N, Franchi A, editors. Pathology of the Head and Neck. Heidelberg, Berlin: Springer; 2016. p.515-38.
9) Van der Laan TP, Iepsma R, Witjes MJ, van der Laan BF, Plaat BE, Halmos GB. Meta-analysis of 701 published cases of sinonasal neuroendocrine carcinoma: the importance of differentiation grade in determining treatment strategy. Oral Oncol 2016;63:1-9.

10) Chang CF, Li WY, Shu CH, Ho CY. Sino-nasal neuro-endocrine carcinoma. Acta Otolaryngol 2010;130(3):392-7.

11) Kao HL, Chang WC, Li WY, Chia-Heng Li A, Fen-Yau Li A. Head and neck large cell neuroendocrine carcinoma should be separated from atypical carcinoid on the basis of different clinical features, overall survival, and pathogenesis. Am J Surg Pathol 2012;36(2):185-92.

12) Maharaj S, Mahomed F. Sinonasal non-small cell neuroendocrine carcinoma the validity of histological grading: case report and a review of the literature. Otolaryngol Case Rep 2019;10:32-5.

13) Fitzek MM, Thornton AF, Varvares M, Ancukiewicz M, Mcintyre J, Adams J, et al. Neuroendocrine tumors of the sinonasal tract. Results of a prospective study incorporating chemotherapy, surgery, and combined proton-photon radiotherapy. Cancer 2002;94(10):2623-34.

14) Bhattacharyya N, Thornton AF, Joseph MP, Goodman ML, Amrein PC. Successful treatment of esthesioneuroblastoma and neuroendocrine carcinoma with combined chemotherapy and proton radiation: results in 9 cases. Arch Otolaryngol Head Neck Surg 1997;123(1):34-40.

15) Babin E, Rouleau V, Vedrine PO, Toussaint B, de Raucourt $\mathrm{D}$, Malard $\mathrm{O}$, et al. Small cell neuroendocrine carcinoma of the nasal cavity and paranasal sinuses. J Laryngol Otol 2006;120(4):289-97.

16) Van der Laan TP, Bij HP, Van Hemel BM, Plaat BE, Wedman J, Van der Laan BF, et al. The importance of multimodality therapy in the treatment of sinonasal neuroendocrine carcinoma. Eur Arch Otorhinolaryngol 2013;270(9):2565-8.

17) Lee DH, Cho HH, Cho YB. Typical carcinoid tumor of the nasal cavity. Auris Nasus Larynx 2007;34(4):537-9.

18) Mhawej R, Farah C, Haddad A, Tabchy B. Primary neuroendocrine tumors of the ear, nose and throat: a report of three cases and a review of the literature. Oncol Lett 2015;10(4):2533-36.

19) Likhacheva A, Rosenthal DE, Hanna E, Kupferman M, Demonte F, El-Naggar AK. Sinonasal neuroendocrine carcinoma: impact of differentiation status on response and outcome. Head Neck Oncol 2011;3:32.

20) Vandist V, Deridder F, Waelput W, Parizel PM, Van de Heyning P, Van Laer C. A neuroendocrine tumour of the sphenoid sinus and nasopharynx: a case report. B-ENT 2010;6(2):147-51.

21) Weinreb I, Perez-Ordoñez B. Non-small cell neuroendocrine carcinoma of the sinonasal tract and nasopharynx; report of 2 cases and review of the literature. Head Neck Pathol 2007;1(1):21-6.

22) Stephenson KA, Lubbe DE. Primary atypical carcinoid tumour of the sphenoid sinus rostrum. Case Rep Otolaryngol 2014;2014:753964. 